\title{
Arrow of Time or Providence Divine? An Amusing But Thought Provoking Poem on Relative Positioning of Primary Motor and Sensory Cortices of Human Brain
}

\author{
Amitava Biswas \\ Department of Speech and Hearing Sciences, University of Southern Mississippi, Hattiesburg, MS, USA
}

\section{The Poem}

My question in Figure 1

Is about a neural phenomenon.

To give you a little cue,

Citing references [1] and [2].

Did you ever worry

Over any scary

Exam neuro introductory

Cramming too much memory?

If you aren't too shy

Do you ask anyone why?

And which is ahead,

Inside your head?

Motor cortex primary

Or the somatosensory?

To help your memory

Recall Eddington's theory

With metaphor archery

Stamping time history.

Whether or not really

It has any divine eerie.

Although not $100 \%$ exceptional,

Like most of our theories in general,

See an arrow of time in this rudimental,

A phenomenon that's essentially neural.

Back is past, front is future,

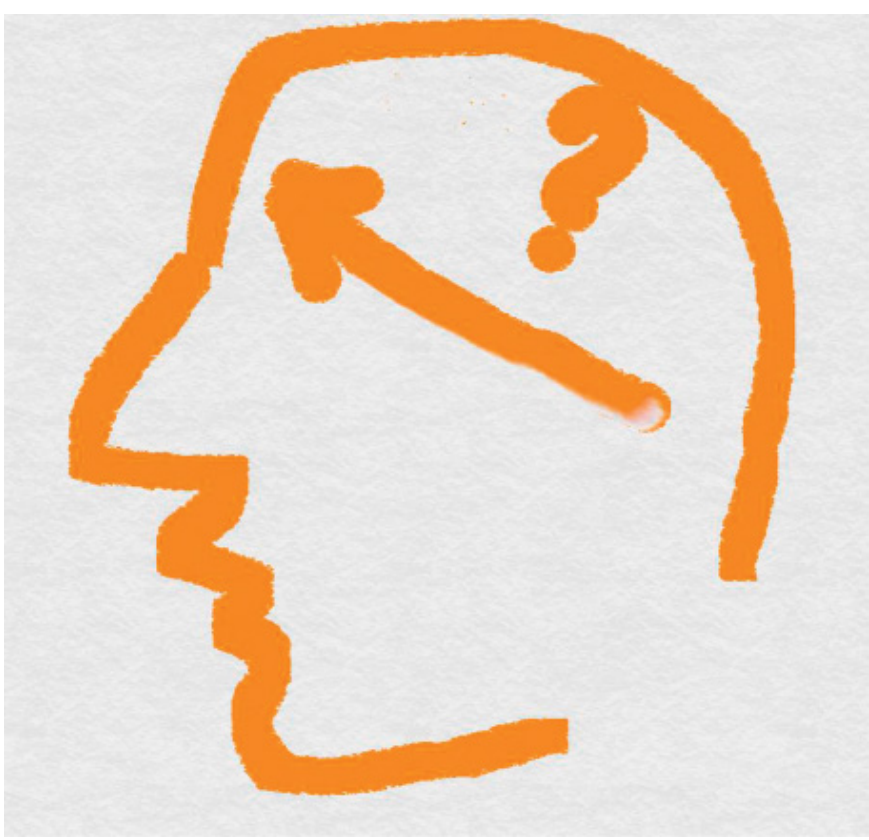

Fig. 1. Arrow of time or providence divine?

That is our point in this conjecture!

If future is front and past is back,

Then present is central for any logical stack.

If present is assumed around sulcus central,

Pre and post relate pretty logical.

\section{KARGER}

(C) 2017 S. Karger AG, Basel

E-Mail karger@karger.com

www.karger.com/aon
Amitava Biswas

The University of Southern Mississippi

Department of Speech and Hearing Sciences

118 College Drive \#5092 Hattiesburg, MS 39406-0001 (USA)

E-Mail Amitava.Biswas@usm.edu 
Two evidential samples,

We mean examples:

When can you text me an SMS?

Anytime past is out of sense!

Anytime ahead in the future

Is a possible answer!

When your brain is texting using the muscles of your finger,

It is engaging forward for immediate future.

It is just ahead of the central sulcus

Predictable predecessor precentral gyrus!

If you've no ESP,

And sensing a sting of a honeybee,

You are not sensing a forecast,

But your recent past.

Recording behind of central sulcus,

Posteriorly posted postcentral gyrus!

This basic theory,

About motor and sensory,

Can be extensible,
If you are flexible!

Even in the cord spinal,

If you mix-up ventral dorsal,

Before your exam final,

Keep this point vital.

Remember motor and sensory,

As described in above category,

Broadly map respectively

Anteriorly and posteriorly,

By only coincidentally

Or just by divine providence entirely?

\section{Acknowledgments}

This work has benefited from faculty start-up funds granted by the University of Southern Mississippi. Several individuals have helped this concept at some point in time or other, especially Dr. Steven Barlow, Dr. Steven Cloud, Dr. Edward Goshorn, Dr. Anthony Salvatore, and Dr. Charles Watson.

\section{References}

1 Eddington AS: The Nature of the Physical World. New York, Macmillan Company, 1927.
2 Penfield W, Boldfrey E: Somatic motor and sensory representation in the cerebral cortex of man as studied by electrical stimulation. Brain 1937;60:389-443. 